\title{
Stress Echocardiography
}

National Cancer Institute

\section{Source}

National Cancer Institute. Stress Echocardiography. NCI Thesaurus. Code C80407.

An image of the heart produced by ultrasonography under conditions intended to elicit signs and symptoms of myocardial ischemia. Conditions often include exercise, pharmacologic agents or pacing. 